\title{
Circulating tumor cells expressing cancer stem cell marker CD44 as a diagnostic biomarker in patients with gastric cancer
}

\author{
TORU WATANABE, TOMOYUKI OKUMURA, KATSUHISA HIRANO, TETSUJI YAMAGUCHI, \\ SHINICHI SEKINE, TAKUYA NAGATA and KAZUHIRO TSUKADA
}

\begin{abstract}
Department of Surgery and Science, Graduate School of Medicine and Pharmaceutical Sciences for Research, University of Toyama, Toyama 930-0194, Japan
\end{abstract}

Received May 30, 2015; Accepted October 7, 2016

DOI: $10.3892 / \mathrm{ol} .2016 .5432$

\begin{abstract}
Epithelial cell adhesion molecule (EpCAM) is a marker for circulating tumor cells (CTCs) in various types of cancer, while cluster of differentiation 44 (CD44) is a marker for gastric cancer (GC) stem cells. To evaluate the clinical significance of CD $44^{+}$CTCs in patients with GC in the present study, the number of EpCAM ${ }^{+} \mathrm{CD}_{4} 4^{+}$and $\mathrm{EpCAM}^{+} \mathrm{CD} 44$ cells were detected in the peripheral blood of $26 \mathrm{GC}$ patients and 12 healthy volunteers using flow cytometry. The number (mean \pm standard deviation) of $\mathrm{EpCAM}^{+} \mathrm{CD} 44^{+}$cells in the $\mathrm{GC}$ patients and healthy volunteers was $69.9 \pm 52.0$ and $0.91 \pm 2.10$, respectively $(\mathrm{P}=0.0001)$, while that of $\mathrm{EpCAM}^{+} \mathrm{CD} 44^{-}$cells was $59.1 \pm 88.0$ and 9.83 \pm 9.91 , respectively $(\mathrm{P}=0.0313)$. The sensitivity and specificity of $\mathrm{EpCAM}^{+} \mathrm{CD} 44^{+}$cell detection for the identification of GC patients were 92.3 and $100 \%$, respectively. By contrast, the values of EpCAM+CD44- cell detection were 76.9 and $83.3 \%$, respectively. The number of $\mathrm{EpCAM}^{+} \mathrm{CD} 44^{+}$cells in the GC patients was correlated with the disease stage $(\mathrm{P}=0.0423)$, the depth of the tumor $(\mathrm{P}=0.0314)$ and venous invasion $(\mathrm{P}=0.0184)$ in the resected tumor specimens, while the number of EpCAM+CD44- cells did not correlate with any clinicopathological factors. The number of EpCAM ${ }^{+} \mathrm{CD} 44^{+}$cells significantly decreased following surgical resection of the tumor or induction of systemic chemotherapy. Additionally, atypical cells with a high nuclear to cytoplasmic ratio were morphologically detected in the sorted EpCAM ${ }^{+} \mathrm{CD} 44^{+}$cells. These results suggested that $\mathrm{CD}_{4} 4^{+} \mathrm{CTCs}$, but not CD44- $\mathrm{CTCs}$, reflect the malignant status of the primary tumor in patients with GC, providing a candidate biomarker for diagnosis and treatment response.
\end{abstract}

Correspondence to: Dr Tomoyuki Okumura, Department of Surgery and Science, Graduate School of Medicine and Pharmaceutical Sciences for Research, University of Toyama, 2630 Sugitani, Toyama 930-0194, Japan

E-mail: okumura@med.u-toyama.ac.jp

Key words: gastric cancer, flow cytometry, epithelial cell adhesion molecule, cluster of differentiation 44 , circulating tumor cells

\section{Introduction}

Gastric cancer (GC) is the second leading cause of cancer-associated mortality worldwide (1). Although recent treatment advances have improved the clinical outcome of patients with GC (2-5), the prognosis of those with advanced stage disease is poor due to a high incidence of metastasis and recurrence. Metastasis contributes significantly to high cancer mortality rates, and thus the development of sensitive, specific and convenient diagnostic methods for the early detection of metastasis is paramount to reduce these mortality rates (6).

In recent years, attention has been focused on the proportion of circulating tumor cells (CTCs) as an early detection marker for metastasis (6). The most widely studied CTC detection method is based on immunomagnetic enrichment with epithelial cell adhesion molecule (EpCAM) antibodies and subsequent immunological identification using cytokeratin (CK) antibodies $(7,8)$. EpCAM is a cell-surface molecule involved in cell-to-cell adhesion that is highly expressed in the majority of epithelial carcinomas (8). CKs form intermediate filaments in epithelial cells, and are used as specific markers for tumor cells of epithelial origin $(9,10)$.

In a prospective investigation, quantification of CTCs using this method revealed that CTCs were an independent prognostic factor in patients with advanced colorectal (11), breast (12) and prostate (13) cancer.

More recently, it has been hypothesized that functional heterogeneity may account for the fact that not all cancer cells in solid tumors have a similar ability to drive oncogenesis (14). This observation has led to the cancer stem cell (CSC) hypothesis, which suggests that CSCs within the tumor can self-renew and proliferate to form new tumors, and could be associated with cancer metastasis (14).

A recent study indicated that a portion of CTCs have characteristics reminiscent of CSCs; these were termed circulating tumor stem cells (CTSCs) (15). Compared with CTCs, CTSCs may be a more accurate prognostic factor, as cancer growth is dependent on cancer stem cells (CSCs), which are typically resistant to chemotherapy (16).

Cluster of differentiation 44 (CD44) was previously reported to be a useful CSC marker in MKN45, MKN74 and NCI-N-87 GC cell lines (17); the CD44+ cell fraction could generate more spheroid colonies compared with the CD44- cell fraction. 
Furthermore, the $\mathrm{CD} 44^{+} \mathrm{GC}$ cells showed enhanced tumorigenicity, chemoresistance and radioresistance in vivo, compared with the CD44- GC cells (17). In addition, a meta-analysis reported that CD44 expression in primary tissues was correlated with lymph node metastasis and venous invasion (18). In particular, the CD44 exon 6 and exon 8-10 variants were correlated with hematogenous metastasis $(19,20)$.

The primary objective of the present study was to detect CD $44^{+}$CTCs in the peripheral blood of patients with GC in order to determine the clinical significance of CD44 as a biomarker of diagnosis and treatment response.

\section{Materials and methods}

Patients. The present study included 26 patients with GC who were admitted to Toyama University Hospital (Toyama, Japan) between April 2014 and December 2014. The patient population consisted of 17 men and 9 women, with a median age of 72.69 years (range, $48-87$ years). A total of 7 patients presented with stage IA disease, 5 with stage IIA, 1 with stage IIB, 3 with stage IIIA, 2 with stage IIIB, 3 with stage IIIC and 5 with stage IV. With regard to treatment, 1 patient underwent chemotherapy and 25 patients underwent gastrectomy (15 distal gastrectomies, 8 total gastrectomies, 1 partial gastrectomy and 1 remnant gastrectomy). Clinicopathological classifications were determined by the International Union Against Cancer Tumor-Node-Metastasis criteria (7th edition) (21). The response to chemotherapy was measured using computed tomography (CT) and was evaluated according to the Response Evaluation Criteria in Solid Tumors (version 1.1) (22). Additionally, 10 healthy volunteers, aged 26-81 years (median, 40.0 years), were recruited as negative controls. All subjects provided informed consent for study inclusion and were enrolled following Institutional Review Board (Toyama University Hospital) approved protocols.

Sample preparation. Blood samples $(6 \mathrm{ml})$ were collected in 3-ml ethylenediaminetetraacetic acid (EDTA) tubes. Peripheral blood samples were extracted from each patient during general anesthesia via a median cubital vein or the arterial pressure line prior to gastrectomy. In the single patient who underwent chemotherapy, the blood was extracted via a median cubital vein. Peripheral blood samples were extracted from each healthy volunteer during general anesthesia via a median cubital vein. Samples were processed and evaluated as soon as possible following collection.

Elimination of red blood cells from samples. Blood samples were transferred to 5-ml tubes containing anticoagulant with EDTA, and were diluted by the addition of an equal volume $(3 \mathrm{ml})$ of phosphate-buffered saline (PBS) containing $2 \%$ fetal bovine serum (FBS). Next, $6 \mathrm{ml}$ of the diluted blood sample was subsequently overlaid on a 4-ml Lymphoprep ${ }^{\mathrm{TM}}$ (Cosmo Bio Co, Tokyo, Japan) placed in a $15-\mathrm{ml}$ centrifuge tube. The mixing of blood and separation fluid was avoided, and the tube was capped to prevent the formation of aerosols. The tubes were spun at $800 \times \mathrm{g}$ for $20 \mathrm{~min}$ at room temperature in a swing-out rotor centrifuge. After spinning, mononuclear cells were removed from the distinct band at the sample/medium interface using a Pasteur pipette without disturbing the upper layer. Mononuclear cells were diluted in $2 \mathrm{ml}$ PBS containing $2 \% \mathrm{FBS}$, and the cells were subsequently pelleted by spinning at $250 \mathrm{x} \mathrm{g}$ for $5 \mathrm{~min}$ at $25^{\circ} \mathrm{C}$.

Flow cytometry by fluorescence-activated cell sorting (FACS) and sample analysis. For staining, human monoclonal EpCAM-allophycocyanin (APC) (clone HEA125; MACS Miltenyi Biotec, Cologne, Germany) and CD44-fluorescein isothiocyanate (FITC; clone IM7.8.1; MACS Miltenyi Biotec) antibodies were used. As negative controls, mouse IgG1-APC and FITC (clone IS5-21F5; MACS Miltenyi Biotec) isotype control antibodies were used. All antibodies were diluted 1:100 in $200 \mu \mathrm{l}$ PBS containing 2\% FBS. At 15 min post-staining, the cells were diluted in PBS containing 2\% FBS and pelleted by spinning at $250 \mathrm{x} g$ for $5 \mathrm{~min}$ at $4^{\circ} \mathrm{C}$. Samples were analyzed on a FACScanto ${ }^{\mathrm{TM}}$ II flow analyzer (BD Biosciences, Franklin Lakes, NJ, USA). A sample for sorting was analyzed on a FACSAria $^{\mathrm{TM}}$ flow sorter (BD Biosciences), and sorted into a 5-ml tube with $1 \mathrm{ml}$ PBS containing 2\% FBS. These materials were processed as follows.

Examination of sorted cells. Sorted $\mathrm{EpCAM}^{+} \mathrm{CD} 44^{+}$cells were washed twice and diluted in $200 \mu 1$ cold PBS containing $2 \%$ FBS. Slides and filters were placed into appropriate slots in a cytospin chamber (Stat Spin; Beckman Coulter, Tokyo, Japan) with the cardboard filters facing the center. In the event of few cells being available, $100 \mu \mathrm{l}$ cold PBS containing $2 \%$ FBS was first placed in each cytospin, which was then spun at $250 \times g$ for $5 \mathrm{~min}$ at $25^{\circ} \mathrm{C}$ to pre-wet the filter, allowing more cells to reach the slide. In addition, correct alignment of the filter/slide interface was ensured. For each sample, $200 \mu 1$ was added to the appropriate wells of the cytospin, lids were applied and centrifugation was performed at $250 \mathrm{x} g$ for $5 \mathrm{~min}$ at $25^{\circ} \mathrm{C}$. Subsequently, the filters were removed taking care not to disturb the smears on the slides.

Each slide was examined under a microscope to check cell adherence, morphology and monolayer formation. Slides were dried overnight in a desiccator and evaluated using a transmitted light microscope (BX61/DP70; Olympus, Tokyo, Japan) equipped with an ultraviolet light source and filters. A cytotechnologist at the hospital analyzed the sorted cells with regard to the nuclear to cytoplasmic ratio, the overall cell size and the size of the nucleolus.

Immunohistochemical evaluation of primary tumor tissues. All 25 primary tumors resected during gastrectomy were evaluated immunohistochemically. Sections $(5 \mu \mathrm{m})$ from formalin-fixed paraffin-embedded tissues were mounted on positively charged slides then dewaxed in xylene and rehydrated. Specimens were pretreated with KN9 buffer (code KN-09001; Pathology Institute, Toyama, Japan) for $40 \mathrm{~min}$ at $95^{\circ} \mathrm{C}$ in a water bath, cooled at room temperature for $20 \mathrm{~min}$ and washed with distilled water (DW). The slides were then blocked for $10 \mathrm{~min}$ in 3\% peroxide DW solution, washed with DW and blocked for $5 \mathrm{~min}$ in $\mathrm{KN}$ buffer (code KN-09002; Pathology Institute). The slides were stained with EpCAM (clone VU1D9; Cell Signaling Technology Japan, Tokyo, Japan) mouse monoclonal antibody (mAb; dilution 1:500; Cell Signaling Technology), CD44 mouse mAb (clone 156-3C11; dilution 1:400; Cell Signaling Technology) or CK-Oscar mouse 
Table I. Receiver operating characteristic analysis of the $\mathrm{EpCAM}^{+} \mathrm{CD}_{4} 4^{+}$and $\mathrm{EpCAM}^{+} \mathrm{CD} 44^{-}$circulating tumor cell counts in the peripheral blood.

\begin{tabular}{|c|c|c|c|c|}
\hline Cell status & $\begin{array}{c}\text { Sensitivity, } \\
\%\end{array}$ & $\begin{array}{c}\text { Specificity, } \\
\%\end{array}$ & AUC & P-value \\
\hline $\mathrm{EpCAM}^{+} / \mathrm{CD} 44^{+}$ & 97.4 & 100.0 & 0.9744 & $<0.0001$ \\
\hline $\mathrm{EpCAM}^{+} / \mathrm{CD} 44^{-}$ & 76.9 & 83.3 & 0.8317 & 0.0005 \\
\hline
\end{tabular}

EpCAM, epithelial cell adhesion molecule; CD44, cluster of differentiation 44; AUC, area under the curve.

A

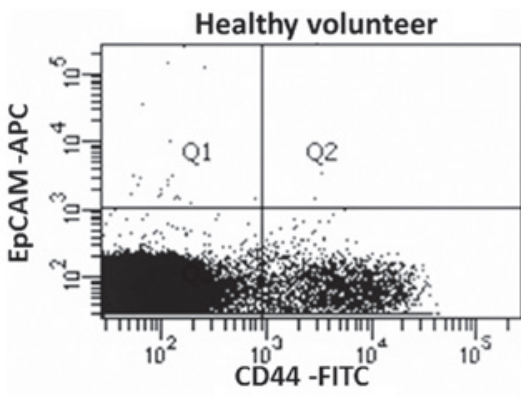

B

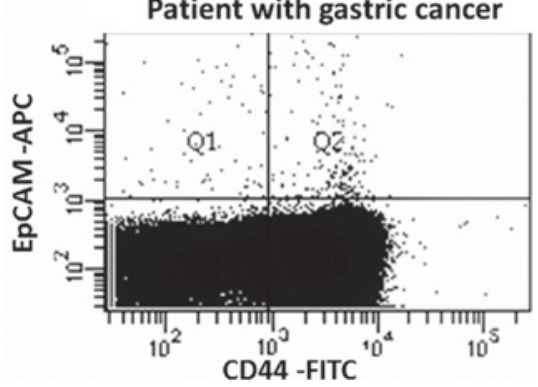

Figure 1. A comparison of $\mathrm{EpCAM}^{+}$and/or $\mathrm{CD} 44^{+} \mathrm{CTC}$, circulating tumor cell counts in the peripheral blood of healthy volunteers and patients with gastric cancer. Fluorescence-activated cell sorting data from (A) a healthy volunteer and (B) a patient with gastric cancer. All WBCs are EpCAM- cells and CD44 was expressed not only on circulating stem cells, but also in a proportion of WBCs. Thus, typical WBCs are found in Q3 or Q4. Q1 shows $\mathrm{EpCAM}^{+} \mathrm{CD} 44^{-}$cells and Q2 shows $\mathrm{EpCAM}^{+} \mathrm{CD} 44^{+}$cells. WBC, white blood cell; EpCAM, epithelial cell adhesion molecule; CD44, cluster of differentiation 44; APC, allophycocyanin; FITC, fluorescein isothiocyanate.

mAb (clone BSB6181; dilution 1:200; Bio SB, Shiga, Japan) for $30 \mathrm{~min}$. CK-Oscar identifies cytokeratins 7, 8, 18 and 19, and has been used to distinguish epithelial carcinoma from non-epithelial tissues (23-29). Slides were then counterstained using the peroxidase-conjugated Envision technique (Envision plus Dual Link Horseradish Peroxidase; DAKO, Glostrup, Denmark). Staining for EpCAM or CD44 was defined as positive when cells were also positive for CK-Oscar.

Statistical analyses. Comparisons between groups were evaluated using paired and unpaired Student's t-tests. A $\mathrm{P}<0.05$ was considered to indicate a statistically significant difference. All data are shown as the mean \pm standard deviation. Receiver-operating-characteristic (ROC) curves and the area-under-the-curve (AUC) were used to assess the feasibility of using $\mathrm{EpCAM}^{+} \mathrm{CD} 44^{+}$and $\mathrm{EpCAM}^{+} \mathrm{CD} 44^{-}$cell counts as

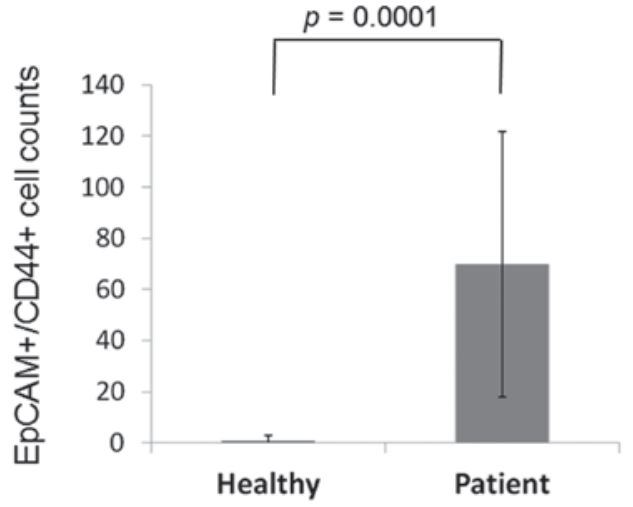

Figure 2. A comparison of $\mathrm{EpCAM}^{+} \mathrm{CD} 44^{+} \mathrm{CTC}$ counts in the peripheral blood of healthy volunteers and patients with GC. Mean data are shown. All patients with $\mathrm{GC}$ had EpCAM ${ }^{+} \mathrm{CD} 44^{+} \mathrm{CTCs}$, whereas only 2 out of 10 healthy volunteers had EpCAM ${ }^{+} \mathrm{CD} 44^{+}$CTCs. GC, gastric cancer; EpCAM, epithelial cell adhesion molecule; CD44, cluster of differentiation 44; CTC, circulating tumor cell.

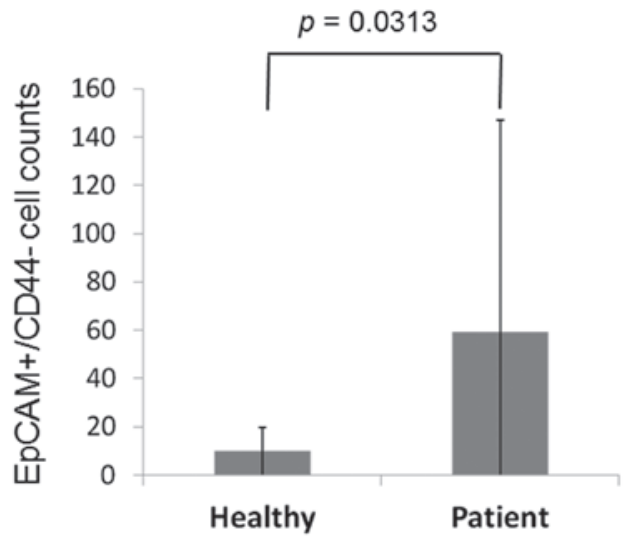

Figure 3. A comparison of EpCAM+CD44- CTC counts in the peripheral blood of healthy volunteers and patients with GC. Mean data are shown. EpCAM+CD44- CTCs were detected in all subjects.

a measure of CTC number in patients with GC. All statistical analyses were performed using JMP version 11 software (Statistical Discovery, Tokyo, Japan).

\section{Results}

A comparison of EpCAM+CD44+ and EpCAM+CD44- cell proportions in the peripheral blood between patients with $G C$ and healthy volunteers. A representative figure of the comparison of the proportion of $\mathrm{EpCAM}^{+} \mathrm{CD} 44^{+}$and $\mathrm{EpCAM}^{+} \mathrm{CD} 44^{-}$cells in the peripheral blood between patients and healthy controls is shown in Fig. 1. EpCAM ${ }^{+} \mathrm{CD} 44^{+}$ cells were detected in 3 out of $12(25.0 \%)$ healthy volunteers and 26 out of $26(100.0 \%)$ patients, with mean cell counts of $0.91 \pm 2.10$ and $69.9 \pm 52.0$, respectively $(\mathrm{P}=0.0001$; Fig. 2). EpCAM ${ }^{+} \mathrm{CD}_{4} 4^{-}$cells were detected in 12 out of $12(100.0 \%)$ healthy volunteers and 26 out of $26(100.0 \%)$ patients, with mean cell counts of $9.83 \pm 9.91$ and $59.1 \pm 88.0$, respectively ( $\mathrm{P}=0.0313$; Fig. 3).

With ROC curve analysis to diagnose GC, the largest AUC for $\mathrm{EpCAM}^{+} \mathrm{CD} 44^{+}$cell counts was 0.9744 , and the optimal sensitivity and specificity were 92.3 and $100.0 \%$, respectively 
Table II. Mean EpCAM ${ }^{+} \mathrm{CD} 44^{+}$and $\mathrm{EpCAM}^{+} \mathrm{CD} 44^{-} \mathrm{CTC}$ counts in the peripheral blood for each clinicopathological characteristic.

\begin{tabular}{|c|c|c|c|c|c|}
\hline Characteristic & $\mathrm{n}$ & $\mathrm{EpCAM}^{+} / \mathrm{CD}_{4} 4^{+} \mathrm{CTC}$ count & P-value & $\mathrm{EpCAM}^{+} / \mathrm{CD} 44^{-} \mathrm{CTC}$ count & P-value \\
\hline Gender (male/female) & $8 / 17$ & $59.1 / 89.8$ & 0.2001 & $68.2 / 41.1$ & 0.3316 \\
\hline Age $(<75 />75$ years $)$ & $12 / 13$ & $63.4 / 74.9$ & 0.5995 & $67.8 / 50.6$ & 0.6338 \\
\hline pStage (I/II-IV) & $6 / 19$ & $43.2 / 77.1$ & $0.0423^{\mathrm{a}}$ & $32.1 / 68.2$ & 0.0846 \\
\hline pT (1/2-4) & $7 / 18$ & $44.1 / 78.6$ & $0.0314^{\mathrm{a}}$ & $30.7 / 70.8$ & 0.0682 \\
\hline pN (-/+) & $14 / 11$ & $68.9 / 69.0$ & 0.4974 & $47.5 / 74.9$ & 0.2445 \\
\hline ly $(-/+)$ & $6 / 19$ & $79.3 / 65.6$ & 0.6708 & $37.8 / 62.6$ & 0.1314 \\
\hline $\mathrm{V}(-/+)$ & $8 / 17$ & $43.1 / 81.1$ & $0.0184^{\mathrm{a}}$ & $28.8 / 74.0$ & 0.0538 \\
\hline Her2 (-/+) & $10 / 9$ & $54.2 / 61.8$ & 0.3667 & $35.6 / 104.0$ & 0.0880 \\
\hline CEA (-/+) & $20 / 5$ & $74.0 / 48.6$ & 0.9517 & $39.5 / 139.8$ & 0.1392 \\
\hline CA19-9 (-/+) & $22 / 3$ & $65.4 / 97.3$ & 0.1624 & $51.5 / 118.3$ & 0.2230 \\
\hline
\end{tabular}

${ }^{\mathrm{a}} \mathrm{P}<0.05 \mathrm{CTC}$, circulating tumor cell; ly, lymphatic invasion; v, venous invasion; Her2, epidermal growth factor receptor 2; CEA, carcinoembryonic antigen; CA19-9, cancer antigen 19-9; pStage, pathological stage; pT, pathological wall invasion depth; pN, pathological lymph node metastasis.
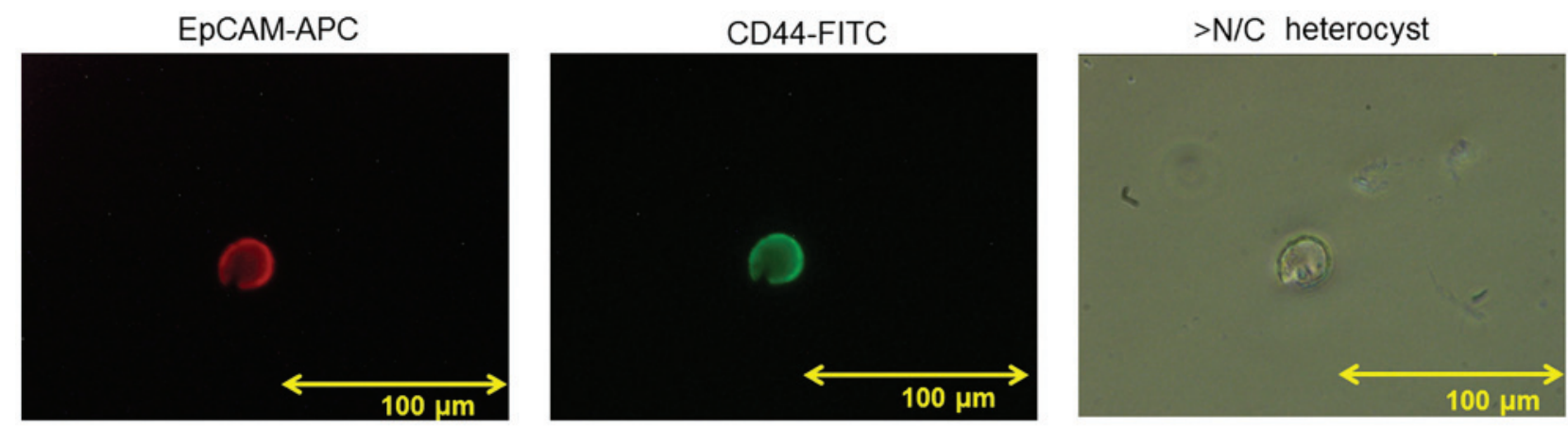

Figure 4. Immunofluorescent staining of sorted $\mathrm{EpCAM}^{+} \mathrm{CD} 44^{+}$circulating tumor cells. This cell shows strong staining with EpCAM-APC (red staining) and CD44-FITC (green staining). The cell was identified as a $20-\mu \mathrm{m}$ heterocyst with a high nuclear to cytoplasmic ratio (original magnification, $\mathrm{x} 400$ ). EpCAM, epithelial cell adhesion molecule; CD44, cluster of differentiation 44; APC, allophycocyanin; FITC, fluorescein isothiocyanate; >N/C, high nuclear to cytoplasmic ratio.

(Table I). The largest AUC for EpCAM+CD44 cell counts was 0.8317 , and the optimal sensitivity and the specificity were 76.9 and $83.3 \%$, respectively (Table I).

A comparison of the proportions of EpCAM+CD44 and EpCAM ${ }^{+} C D 44-C T C s$ in the peripheral blood of patients with $G C$. Clinicopathological characteristics of the patients who underwent gastrectomy and their cell counts in the peripheral blood are shown in Table II. Mean EpCAM ${ }^{+} \mathrm{CD} 44^{+}$cell counts were correlated with pathological stage (pStage), pathological wall invasion depth and venous invasion (v) factors $(\mathrm{P}=0.0423,0.0314$ and 0.0184 , respectively). By contrast, mean $\mathrm{EpCAM}^{+} \mathrm{CD} 44^{-}$cell counts did not show any correlation with the clinicopathologial factors (Table II).

Sorted $\mathrm{EpCAM}^{+} \mathrm{CD} 44^{+}$CTCs. EpCAM ${ }^{+} \mathrm{CD} 44^{+} \mathrm{CTCs}$ were evaluated in 1 case of GC. A representative figure of EpCAM-APC (red) and CD44-FITC (green) cell staining is shown in Fig. 4. The overall cell size was $\geq 20 \mu \mathrm{m}$, the nuclear to cytoplasmic ratio was high and the nucleolus was enlarged. The cell was identified as a heterocyst rather than a white blood cell (WBC), indicating malignant cytology.

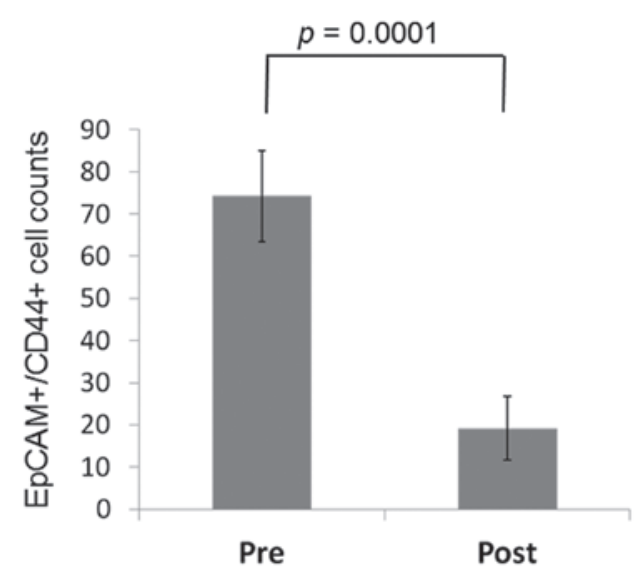

Figure 5. $\mathrm{EpCAM}^{+} \mathrm{CD} 44^{+} \mathrm{CTC}$ counts pre- and post-gastrectomy. Mean data are shown from the 25 patients who underwent gastrectomy. $\mathrm{EpCAM}^{+} \mathrm{CD} 44^{+} \mathrm{CTC}$ counts decreased in all cases following surgery. EpCAM, epithelial cell adhesion molecule; CD44, cluster of differentiation 44; CTC, circulating tumor cell.

A comparison of EpCAM+CD44+ CTC counts pre- and post-gastrectomy. In 23 of the $25(92.0 \%)$ patients who underwent a gastrectomy, $\mathrm{EpCAM}^{+} \mathrm{CD} 44^{+} \mathrm{CTCs}$ were counted 


\section{CD44}

EpCAM

CK-Oscar

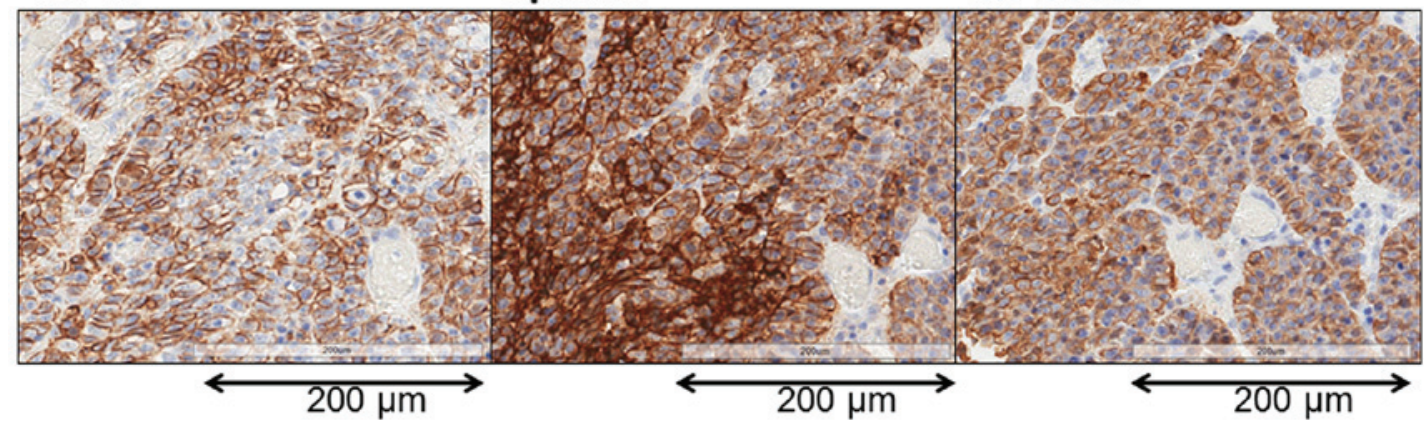

Figure 6. Immunohistochemical evaluation of the resected primary tumor. CK-Oscar staining was used a positive control to indicate tumorous tissue. In advanced GC, almost all cancer cells were stained with EpCAM and CD44. By contrast, in early GC, EpCAM-stained cells were present in almost all cancer cells, but only a few CD44-stained cells were present (original magnification, x400). GC, gastric cancer; EpCAM, epithelial cell adhesion molecule; CD44, cluster of differentiation 44 .

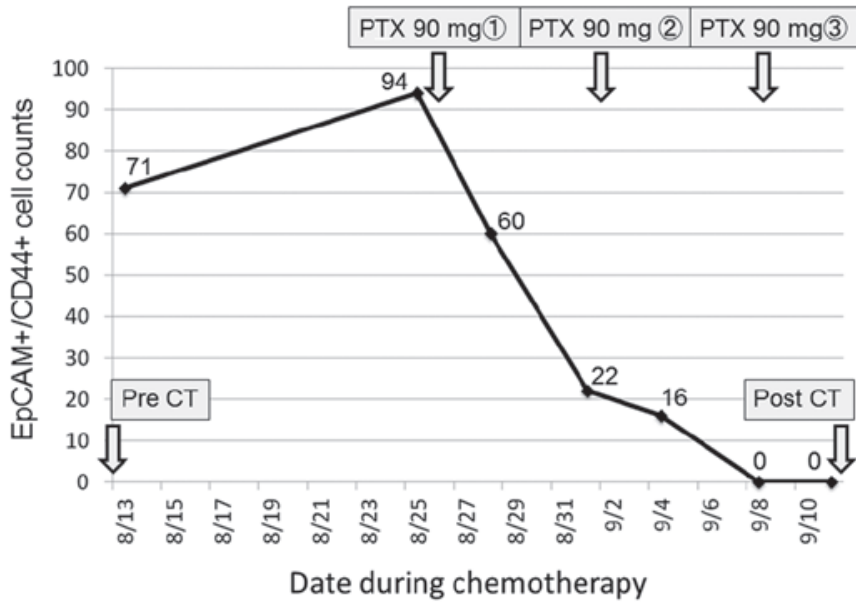

Figure 7. Alterations in EpCAM ${ }^{+} \mathrm{CD} 44^{+}$CTC counts in response to chemotherapy. During second-line PTX-based chemotherapy, EpCAM ${ }^{+} \mathrm{CD} 44^{+} \mathrm{CTC}^{-}$ counts decreased, gradually reaching undetectable levels after 3 weeks. EpCAM, epithelial cell adhesion molecule; CD44, cluster of differentiation 44; CTC, circulating tumor cell; PTX, paclitaxel; CT, computed tomography.

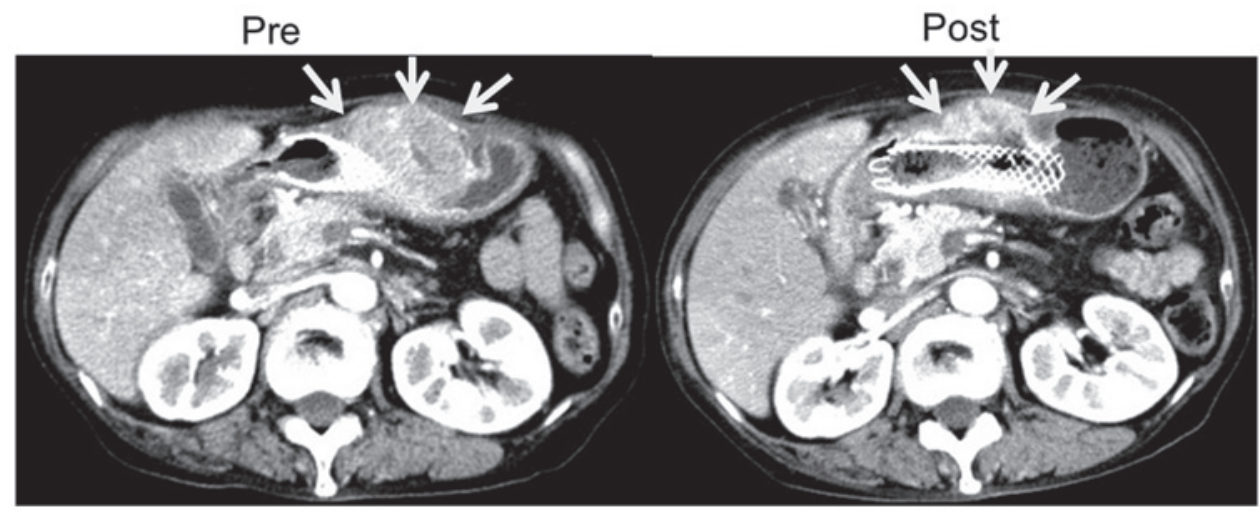

Figure 8. Computed tomography images showing tumor shrinkage following chemotherapy. After one course of second-line paclitaxel-based chemotherapy, according to the Response Evaluation Criteria in Solid Tumors, the main gastric tumor surrounding the stent showed a partial response of $\sim 30 \%$ reduction.

following the gastrectomy, as well as at follow-up, with a mean follow-up time of $96.26 \pm 80.32$ days. Post-gastrectomy, the $\mathrm{EpCAM}^{+} \mathrm{CD} 44^{+} \mathrm{CTC}$ counts were decreased in 21 out of $23(91.3 \%)$ patients to $19.2 \pm 7.48$ cells compared with a pregastrectomy count of $74.2 \pm 10.8$ cells $(\mathrm{P}=0.0001)$ (Fig. 5).
Immunohistochemical evaluation of resected primary tumor tissues. A representative image showing EpCAM and CD44 staining of the primary tumor is shown in Fig. 6. EpCAM and CK-Oscar staining were detected in all the nucleated tumor cells in all 25 patients. By contrast, although CD44 was 
detected in all 25 patients, the expression was distributed only in a limited region of the tumor cells.

A comparison of EpCAM ${ }^{+} C D 44^{+} C T C$ counts pre-and post-chemotherapy. The patient who underwent chemotherapy had been treated previously with first-line chemotherapy for an inoperable tumor, but showed disease progression. After the patient was admitted to Toyama University Hospital, weekly paclitaxel at a dose of $80 \mathrm{mg} / \mathrm{m}^{2} /$ day (90 mg/day) was administered as a second-line chemotherapy. The peripheral blood $\mathrm{EpCAM}^{+} \mathrm{CD} 44^{+} \mathrm{CTC}$ count was measured 7 times during chemotherapy. The proportion of $\mathrm{EpCAM}^{+} \mathrm{CD} 44^{+} \mathrm{CTCs}$ gradually decreased during chemotherapy until they could no longer be detected (Fig. 7). After one course of chemotherapy, CT images showed a partial response in that the size of the main gastric tumor surrounding the stent was decreased by $30 \%$, and there was no development of new lesions (Fig. 8).

\section{Discussion}

The present study evaluated the association between the CTCs that express cancer stem cell marker CD44 and clinicopathological factors in patients with GC. The results demonstrated that EpCAM ${ }^{+} \mathrm{CD} 44^{+} \mathrm{CTC}$ counts detected by FACS correlated with pathological $\mathrm{T}$ and $\mathrm{v}$ factors. The number of EpCAM ${ }^{+} \mathrm{CD} 44^{+}$CTCs was significantly reduced following surgical resection of the primary tumor or chemotherapy.

In healthy volunteers, the mean number of total $\mathrm{EpCAM}^{+}$ CTCs $\left(\mathrm{EpCAM}^{+} \mathrm{CD} 44^{+}\right.$plus $\left.\mathrm{EpCAM}^{+} \mathrm{CD} 44^{-} \mathrm{CTCs}\right)$ in the peripheral blood was $7.6 \pm 5.6$ (data not shown). The presence of these cells was possibly caused by a non-specific immunological reaction or contamination with skin cells (30). In addition, a previous study in mice demonstrated the presence of EpCAM ${ }^{+}$peripheral blood-derived mesenchymal stem cells (PBMSCs) with increased expression of gastric epithelial phenotypic markers (31). In the present study, in the patients with GC, EpCAM ${ }^{+}$CTCs were 114.0 \pm 84.5 (data not shown) and were significantly higher than those in healthy volunteers, reflecting a tumor-bearing state. In patients with $\mathrm{GC}$, the EpCAM ${ }^{+} \mathrm{CD}_{4}{ }^{-} \mathrm{CTC}$ were considered to be CTCs without CSC potential; they could also be WBCs with a non-specific immune reaction, contaminated skin cells and/or transdifferentiated PBMSCs. Further study is required to evaluate the significance of EpCAM ${ }^{+}$CD44- CTCs in the peripheral blood.

EpCAM has been one of the most used cell surface markers to detect CTCs in solid tumors, including metastatic colorectal (32), prostate (33), gastrointestinal (34), and breast (35-38) cancer tumors. The most widely used method to detect CTCs has been the CellSearch ${ }^{\mathrm{TM}}$ system, which relies on immunomagnetic capture of $\mathrm{EpCAM}^{+}$cells in combination with 4' 6-diamidino-2-phenylindole staining, CK immunofluorescence staining and CD45 immunofluorescence staining to differentiate cancer cells of epithelial origin from blood cells, which requires fixation of the cells $(17,39)$.

In the present study, CTCs were detected by flow cytometry, which enables the analysis of the expression of multiple cell surface markers in viable cells. Several methods for the flow cytometric detection of CTCs have been reported previously. In pancreatic cancer patients who underwent surgical resection, CTCs were found to be prognostic markers of survival (40), in which a negative depletion procedure using CD45 and CD34 staining was used to enrich CTCs (41). Other studies demonstrated that $\mathrm{CK}^{+} / \mathrm{CD} 45^{-} \mathrm{CTCs}$ were detected in all examined patients with metastatic lung cancer (42), while healthy volunteers exhibited significantly lower counts (43). However, these previous studies did not describe the gating lines used for the negative controls. In the present study, mouse IgG1-APC and FITC isotype control antibodies were used for negative staining, and the negative gate was defined as follows: In each immunofluorescence stain (APC and FITC), the criteria of the negative control and $99.9 \%$ of all cell counts were defined. A direct comparison of the present findings could not be made with those of other studies due to the different procedures used; however, the CTC counts detected in previous studies were much lower than those in the present study. Further investigations are required to biologically characterize the $\mathrm{EpCAM}^{+} \mathrm{CD} 44^{+}$cells of the present study.

There have previously been studies on the detection of CTSCs in various solid tumors. In colorectal cancer, $\mathrm{CK}^{+} / \mathrm{CD}_{133}{ }^{+}$cells were deemed CTSCs (42). In metastatic breast cancer, $\mathrm{CK}^{+} / \mathrm{CD} 44^{+}$cells were markers for peripheral blood CTCs with a stem-cell phenotype (43). Moreover, CTSCs defined as $\mathrm{CD} 45^{-} \mathrm{EpCAM}^{+} \mathrm{CD} 44^{+} \mathrm{CD} 24^{-}$were shown to be useful for the diagnosis, treatment responsiveness and prognosis of patients with early-stage breast cancer (44). In addition, $\mathrm{CK}^{+} / \mathrm{CD} 44^{+} \mathrm{CTC}$ s were detected in $70.4 \%$ of the CTC-positive GC patients and CD44+ CTCs were significantly associated with tumor location, lymph node metastasis, distant metastasis and recurrence (45). However, there have been no studies on CTSC detection in GC patients using the combination of cell surface markers, EpCAM and CD44, which enables evaluation of viable cell expression. Investigation of the CSC phenotype in sorted EpCAM ${ }^{+} / \mathrm{CD}_{4} 4^{+} \mathrm{CTCs}$ may provide a biological basis of CTSCs in GC.

$\mathrm{EpCAM}^{+} \mathrm{CD}_{4} 4^{+} \mathrm{CTC}$ counts, but not $\mathrm{EpCAM}^{+} \mathrm{CD} 44^{-} \mathrm{CTC}$ counts, were correlated with pathological $\mathrm{T}$ and $\mathrm{v}$ factors in the present study, suggesting a role of CD $44^{+}$CTCs in tumor metastasis. As pathological progression is generally correlated with prognosis in cancer patients (46), the flow cytometric analysis of EpCAM ${ }^{+} \mathrm{CD} 44^{+}$staining could be a novel prognostic tool in patients with GC. Prospective studies with long-term follow-up results are awaited.

In summary, the present investigation using flow cytometry demonstrated that $\mathrm{EpCAM}^{+} \mathrm{CD} 44^{+} \mathrm{CTC}$ counts significantly increased in patients with GC compared with healthy volunteers. The number of $\mathrm{EpCAM}^{+} \mathrm{CD} 44^{+}$ CTCs, but not EpCAM ${ }^{+}$CD44- CTCs, was correlated with disease progression and venous invasion in resected tumor specimens. The number of $\mathrm{EpCAM}^{+} \mathrm{CD} 44^{+} \mathrm{CTC}$ decreased following surgical resection or chemotherapy. CD $44^{+} \mathrm{CTCs}$ are suggested to reflect the malignant potential of the tumor, providing a candidate marker of diagnosis and treatment response in patients with $\mathrm{GC}$, as well as a candidate marker to investigate CTSCs.

\section{Acknowledgements}

The authors would like to thank M. Kawahara for providing excellent technical assistance with flow cytometry, and T. Hori for the cytology evaluation. This study was partly supported 
by a Grant-in-Aid for scientific Research (KAKENHI) (grant no. 23591920).

\section{References}

1. Ferlay J, Shin HR, Bray F, Forman D, Mathers C and Parkin DM: Estimates of worldwide burden of cancer in 2008:GLOBOCAN 2008. Int J Cancer 127: 2893-2917, 2010.

2. Siewert JR, Böttcher K, Roder JD, Busch R, Hermanek P and Meyer HJ: Prognostic relevance of systemic lymph node dissection in gastric carcinoma. German gastric carcinoma study group. Br J Surg 80: 1015-1018, 1993.

3. Ikeda Y, Mori M, Adachi Y, Matsushima T, Sugimachi K and Saku M: Carcinoembryonic antigen (CEA) in stage IV gastric cancer as a risk factor for liver metastasis: A univariate and multivariate analysis. J Surg Oncol 53: 235-238, 1993.

4. Furukawa H, Hiratsuka M, Iwanaga T, Imaoka S, Ishikawa O, Kabuto T, Sasaki Y, Kameyama M, Ohigashi H, Nakamori S, et al: Adjuvant chemotherapy for advanced gastric cancer. Nippon Geka Gakkai Zasshi 97: 312-316, 1996 (In Japanese).

5. Palli D: Epidermiology of gastric cancer: An evaluation of available evidence. J Gastroenterol 35 (Suppl 12): S84-S89, 2000

6. Hughes AD and King MR: Manobiotechnology for the capture and manipulation of circulating tumor cells. Wiley Interdiscip Rev Nanomed Nanobiotechnol 4: 291-309, 2012.

7. Ross AH, Herlyn D, Iliopoulos D and Koprowski H: Isolation and characterization of a carcinoma-associated antigen. Biochem Biophys Res Commun 135: 297-303, 1986.

8. Mostert B, Sleijfer S, Forkens JA and Gratama JW: Circulating tumor cells (CTCs): Detection methods and their clinical relevance in breast cancer. Cancer Treat Rev 35: 463-474, 2009.

9. Moll R, Franke WW, Schiller DL, Geiger B and Krepler R: The catalog of human cytokeratins: Patterns of expression in normal epithelia, tumors and cultured cells. Cell 31: 11-24, 1982.

10. Osborn M, van Lessen G, Weber K, Klöppel G and Altmannsberger M: Differential diagnosis of gastrointestinal carcinomas by using monoclonal antibodies specific for individual keratin polypeptides. Lab Invest 55: 497-504, 1986.

11. Cohen SJ, Punt CJ, Iannotti N, Saidman BH, Sabbath KD, Gabrail NY, Picus J, Morse M, Mitchell E, Miller MC, et al: Relationship of circulating tumor cells to tumor response, progression-free survival, and overall survival in patients with metastatic colorectal cancer. J Clin Oncol 26: 3213-3221, 2008.

12. Cristofanilli M, Budd GT, Ellis MJ, Stopeck A, Matera J, Miller MC, Reuben JM, Doyle GV, Allard WJ, Terstappen LW and Hayes DF: Circulating tumor cells, disease progression, and survival in metastatic breast cancer. N Engl J Med 351: 781-791, 2004.

13. de Bono JS, Scher HI, Montgomery RB, Parker C, Miller MC Tissing H, Doyle GV, Terstappen LW, Pienta KJ and Raghavan D: Circulating tumor cells predict survival benefit from treatment in metastatic castration-resistant prostate cancer. Clin Cancer Res 14: 6302-6309, 2008

14. Reya T, Morrison SJ, Clarke MF and Weissman IL: Stem cells, cancer, and cancer stem cells. Nature 414: 105-111, 2001.

15. Grover PK, Cummins AG, Price TJ, Roberts-Thomson IC and Hardingham JE: Circulating tumor cells: The evolving concept and the inadequacy of their enrichment by EpCAM-based methodology for basic and clinical cancer research. Ann Oncol 25: 1506-1516, 2014

16. Wicha MS and Hayes DF: Circulating tumor cells: Not all detected cells are bad and not all bad cells are detected. J Clin Oncol 29: 1508-1511, 2011

17. Takaishi S, Okumura T, Tu S, Wang SS, Shibata W, Vigneshwaran R, Gordon SA, Shimada Y and Wang TC: Identification of gastric cancer stem cells using the cell surface marker CD44. Stem Cells 27: 1006-1020, 2009.

18. Wang W, Dong LP, Zhang N and Zhao CH: Role of cancer stem cell marker CD44 in gastric cancer: A meta-analysis. Int J Exp Med 7: 5059-5066, 2014

19. Yamaguchi A, Goi T, Yu J, Hirono Y, Ishida M, Iida A, Kimura T, Takeuchi K, Katayama K and Hirose K: Expression of CD44v6 in advanced gastric cancer and its relationship to hematogenous metastasis and long-term prognosis. J Surg Oncol 79: 230-235, 2002.

20. Yamaguchi A, Saito M, Goi T, Iida A, Takeuchi K, Hirose K, Nakagawara G, Urano T, Furukawa K and Shiku H: Exrpession of CD44 variant exons 8-10 in gastric cancer. Jpn J Cancer Res 86: 1166-1171, 1995.
21. Sobin LH, Gospodarowicz MK and Wittekind C. TNM Classification of Malignant Tumours. 7th Edition. Wiley-Blackwell, 2009.

22. Eisenhauer EA, Therasse P, Bogaerts J, Schwartz LH, Sargent D, Ford R, Dancey J, Arbuck S, Gwyther S, Mooney M, et al: New response evaluation criteria in solid tumours: Revised RECIST guideline (version 1.1). Eur J Cancer 45: 228-47, 2009.

23. Battifora $\mathrm{H}$ : Clinical applications of the immunohistochemistry of filamentous proteins. Am J Surg Pathol 12 Suppl 1: 24-42, 1988.

24. Gown AM and Vogel AM: Monoclonal antibodies to human intermediate filament proteins. III. Analysis of tumors. Am J Clin Pathol 84: 413-424, 1985.

25. Knapp AC and Franke WW: Spontaneous losses of control of cytokeratin gene expression in transformed, non-epithelial human cells occurring at different levels of regulation. Cell 59: 67-79, 1989.

26. Lewis JE, Olsen KD and Sebo TJ: Spindle cell carcinoma of the larynx: review of 26 cases including DNA content and immunohistochemistry. Hum Pathol 28: 664-673, 1997.

27. Mueller JD, Stein HJ, Oyang T, Natsugoe S, Feith M, Werner M and Rüdiger Siewert J: Frequency and clinical impact of lymph node micrometastasis and tumor cell microinvolvement in patients with adenocarcinoma of the esophagogastric junction. Cancer 89: 1874-1882, 2000.

28. Sato F, Shimada Y, Li Z, Watanabe G, Maeda M and Imamura M: Lymph node micrometastasis and prognosis in patients with oesophageal squamous cell carcinoma. Br J Surg 88: 426-432, 2001.

29. Miller JM, Astles R, Baszler T, Chapin K, Carey R, Garcia L, Gray L, Larone D, Pentella M, Pollock A, et al: Guidelines for safe work practices in human and animal medical diagnostic laboratories. Recommendations of a CDC-convened, Biosafety Blue Ribbon Panel. MMWR Suppl 61: 1-102, 2012.

30. Paterlini-Brechot $\mathrm{P}$ and Benali NL: Circulating tumor cells (CTC) detection: Clinical impact and future directions. Cancer Lett 253: 180-204, 2007.

31. Okumura T, Wang SSW, Takashi S, Tu SP, Ng V, Ericksen RE, Rustgi AK and Wang TC: Identification of a bone marrow-derived mesenchymal progenitor cell subset that can contribute to the gastric epithelium. Lab Invest 89: 1410-1422, 2009.

32. Matsusaka S, Suenaga M, Mishima Y, Kuniyoshi R, Takagi K, Terui Y, Mizunuma N and Hatake K: Circulating tumor cell as a surrogate marker for determining response to chemotherapy in Japanese patients with metastatic colorectal cancer. Cancer Sci 102: 1188-1192, 2011.

33. Moreno JG, Miller MC, Gross S, Allard WJ, Gomella LG and Terstappen LW: Circulating tumor cells predict survival in patients with metastatic prostate cancer. Urology 65: 713-718, 2005.

34. Hiraiwa K, Takeuchi H, Hasegawa H, Saikawa Y, Suda K, Ando T, Kumagai K, Irino T, Yoshikawa T, Matsuda S, et al: Clinical significance of circulating tumor cells in blood from patients with gastrointestinal cancers. Ann Surg Oncol 15: 3092-3100, 2008.

35. Lianidou ES and Markou A: Circulating tumor cells in breast cancer: Detection system, molecular characterization, and future challenges. Clin Chem 57: 1242-1255, 2011.

36. Nakamura S, Yagata $H$, Ohno S, Yamaguchi $H$, Iwata $H$, Tsunoda N, Ito Y, Tokudome N, Toi M, Kuroi K and Suzuki E: Multi-center study evaluating circutating tumor cells as a surrogate for response to treatment and overall survival in metastatic breast cancer. Breast Cancer 17: 199-204, 2010.

37. Diehn M, Cho RW and Clarke MF: Therapeutic implications of the cancer stem cell hypothesis. Semin Radiat Oncol 19: 78-86, 2009.

38. Meng S, Tripathy D, Frenkel EP, Shete S, Naftalis EZ, Huth JF, Beitsch PD, Leitch M, Hoover S, Euhus D, et al: Circulating tumor cells in patients with breast cancer dormancy. Clin Cancer Res 10: 8152-8162, 2004.

39. Hayes DF and Smerage J: Is there a role for circulating tumor cells in the management of breast cancer? Clin Cancer Res 14 3646-3650, 2008.

40. Sergeant G, van Eijsden R, Roskams T, Van Duppen V and Topal B: Pancreatic cancer circulating tumor cells express a cell motility gene signature that predicts survival after surgery. BMC Cancer 12: 527, 2012.

41. Swennenhuis JF, Reumers J, Thys K, Aerssens J and Terstappen LW: Efficiency of whole genome amplification of single circulating tumor cells enriched by CellSearch and sorted by FACS. Genome Med 5: 106, 2013.

42. Iinuma H, Watanabe T, Mimori K, Adachi M, Hayashi N, Tamura J, Matsuda K, Fukushima R, Okinaga K, Sasako M and Mori M: Clinical significance of circulating tumor cells, including cancer stem-like cells, in peripheral blood for recurrence and prognosis in patients with Dukes' stage B and C colorectal cancer. J Clin Oncol 29: 1547-1555, 2011 
43. Wang NF, Shi L, Li H, Hu Y, Du W, Liu W, Zheng J, Huang S and $\mathrm{Qu}$ X: Detection of circulating tumor cells and tumor stem cells in patients with breast cancer by flow cytometry: A valuable tool for diagnosis and prognosis evaluation. Tumor Biol 33: 561-569, 2012.

44. Theodoropoulos PA, Polioudaki H, Agelaki S, Kallergi G, Saridaki Z, Mavroudis D and Georgoulias V: Circulating tumor cells with a putative stem cell phenotype in peripheral blood of patients with breast cancer. Cancer Lett 288: 99-106, 2010.
45. Li M, Zhang B, Zhang Z, Liu X, Qi X, Zhao J, Jiang Y, Zhai H, Ji Y and Luo D: Stem cell-like circulating tumor cells indicate poor prognosis in gastric cancer. Biomed Res Int 2014: 981261 , 2014.

46. Lu J, Huang CM, Zheng CH, Li P, Xie JW, Wang JB and Lin JX: Consideration of tumor size improves the accuracy of TNM predictions in patients with gastric cancer after curative gastrectomy. Surg Oncol 22: 167-171, 2013. 